\title{
El Colegio de Doncellas Nobles de Toledo. Algunos puntos de sus constituciones
}

\author{
laura Santolaya Heredero *
}

El Arzobispo de Toledo y Cardenal, D. Juan Martínez Siliceo, fundó el "Colegio de Doncellas Nobles" (Doncellas vírgenes de Nuestra Señora de los Remedios) en el año 1551.

Sixto Ramón Parro, en el siglo xix, escribía acerca de los fines de este Colegio que ha durado, como tal, hasta hace pocos años:

"La institución es para cien doncellas que fuesen de sangre limpia (esto era, hijas de cristianos viejos o que no tuviesen en su familia ningún penitenciado por el Tribunal del Santo Oficio), naturales del Arzobispado (excepto seis plazas que pondrían a parientas suyas aunque fuesen de otras diócesis), y de edad desde siete hasta diez años; mas esta limitación de edad se entiende únicamente para entrar en el Colegio, pero las plazas son vitalicias y las disputan, por consiguiente, las agraciadas toda su vida, a no ser que ellas salgan del establecimiento para casarse o entrar en religión, o renuncien voluntariamente, o diesen lugar por justas causas a que se las expulsara del Colegio, lo cual (sea dicho en honor del mismo y de las Colegialas y Directoras que ha tenido) parece no ha llegado todavía a suceder con ninguna... ${ }^{1}$.

Señalaba el fundador la suma que con cada una había que gastarse anualmente y era de $10.000 \mathrm{mrs}$. y mandaba que se dotara a cada una de las que salieran a casarse con $100.000 \mathrm{mrs}$., pero que no se diera nada a las que quisieran entrar monjas porque el objeto de la fundación era "formar allí un plantel de buenas madres de familia, y así es que su

* UNED. Madrid.

1 Parro, Sixto Ramón, Toledo en la mano. Toledo 1857, t. II, págs. 440-441. 
educación debía reducirse a los ordinarios quehaceres de una casa bien regulada y de regulares facultades" ?.

Con todo, el número de Doncellas a lo largo del tiempo varió y solamente el inicial fue el que deseaba el Cardenal Siliceo, esto indico porque ya en la R. Cédula de confirmación y ampliación de las Constituciones de 1566, que es de la que se han extraído los textos que luego se mencionan, se decía que no se admitieran más de treinta y seis porque el Colegio estaba muy endeudado y empeñado.

Efectivamente, no debían ser buenos los tiempos por aquel año porque los primeros veinticinco puntos de la citada $R$. Cédula se fijaban tan sólo en los cometidos del Administrador y del Mayordomo.

Alguno de ellos pretendía limitar los poderes del Administrador: en el punto 13:

"Que de aquí adelante el Administrador que es o fuere del dicho colegio, no pueda gastar en obras ni reparos del dicho colegio de diez mil maravedís arriba, sin parecer y consentimiento de la Rectora que es o fuere y sin parecer del Mayordomo y del Maestro de obras de la casa".

Otros encargaban que no se pagase a supuestas personas beneficiadas en el testamento del fundador. Así el 14:

"Que de aquí adelante no se pague ninguna de las donaciones que parece haber hecho el Cardenal Siliceo por su testamento, de bienes del dicho Colegio por no haber sido su heredero, sino solamente su donatario, y esto antes que se hiciese el dicho testamento, ni a don Lorenzo Siliceo ni a otra persona sin que primero se determine por justicia".

$O$ el 20. "Por cuanto ha constado que el Doctor Santiago hubo y recibió muchos bienes de los que quedaron del dicho Cardenasl pertenecientes al dicho Colegio, mando que dentro de los tres primeros meses siguientes se le pidan, y se le ponga demanda sobre ellos, y se prosiga y fenezca hasta que el dicho Colegio sea restituído de lo que se le debe mediante justicia”.

Hasta aquí algunos trazos formales sobre el Colegio. Sirvan de punto de referencia tan solo. El Colegio era, por lo menos aparentemente, un "reino de mujeres". Señalo esto porque eran la Rectora, la provisora, la escuchadera (qué oficio), o las maestras -o sea, mujeres- las encargadas de hacer cumplir las Constituciones y de dar una específica edu-

2 Ibidem, t. II, pág. 441. 
cación. Poco cambiaron las cosas a lo largo de los años o de las centurias.

La educación se basaba en lo que Carmen Martín-Gaite llama guardar a la mujer; es posible que aquella no se basara en esto tan sólo, pero era punto principal. La escuchadera según el punto 31 debía de ser de confianza y mayor de edad para que pudiera oír lo que las doncellas hablaban en el locutorio "y no consienta ni dé lugar a que se hablen ni traten cosas deshonestas, ni en perjuicio de las dichas doncellas ni del dicho Colegio; y si se hiciere, que lo reprenda y advierta a la dicha Rectora, para que provea lo que se debe hacer".

Para dicha autora la opinión de que la buena fama de la mujer casadera estribaba en su permanente ocultación era cosa unánime en aquellos siglos; con todo habría que hacer algunas matizaciones y decir qué era una ocultación entre visillos porque en el punto 81 se decía que fue voluntad del Cardenal que en determinadas fiestas, fuesen "vistas" dichas doncellas, cosa que "por lo que toca a su casamiento" parecía ser necesaria. Eso sí, a través de rejas.

"Guardar y mostrar» para que eligieran los futuros pretendientes; todo un rito tradicional mantenido de forma inveterada por madres y padres a través de los siglos y que, desde la antropología, tiene todos los requisitos de un comercio.

Y en el guardar, la vigilancia. O «vigilar la guarda». Es curioso observar cómo la vigilancia permaneció en el siglo XIX y entró en el $X X$, según he podido yo misma comprobar según el relato de ciertas personas.

Era una vigilancia cuidada, familiar, para señoritas según las directrices de Mme. de Maintenon. "Para ir instruyendo a las niñas, como deben entrar antes de los diez años, entregan cada nueva colegiala a una de las ya antiguas o de las más crecidas, que con el título de tía suya, la educa en su mismo cuarto o habitación, conservándose siempre entre ellas esa especie de parentesco, en virtud del cual debe la sobrina a la tía el respeto y obediencia, asistencia y cuidado como si fuera su madre».

Era una educación para señoritas. Así hay que interpretar el siguiente párrafo sobre los vestidos de las niñas en los distintos momentos del año dentro de un contexto de elegancia que el Colegio mantuvo a través del tiempo:

«Para todos los actos de comunidad usan una beca o vestido igual todas, de tela de lana blanca, aunque fina; fuera de estos casos pueden vestir el traje ordinario de que usen las señoritas de su clase, siempre honesto; y para salir reunidas en los días y cumpleaños de Reyes o de entradas solemnes de personas reales o de arzobispos de Toledo, y los 
de misterios de Nuestra Señora y Pascuas (que son los únicos en que pueden salit de paseo por Constitución) han de usar precisamente traje negrom ${ }^{3}$.

Las doncellas casaderas que esperaban las fiestas para ser "vistas", tenían que seguir un estricto programa: aprender a labrar y coser, y saber leer y escribir.

No se pretendía lograr bachilleras (según expresión de Carmen MartínGaite) sino mujeres que rigieran hogares medios. Medios en todo: en tamaño, en intereses, en el logro de una vida común media. Eran medios los hogares y medianas-medias las que iban a gobernarlos. No sé si se trataba de fomentar la "aurea mediocritas". Ni tampoco si se intentaba formar hogares con mujeres que "no debian" destacar. Pienso yo que habia una especie de miedo hacia las mujeres decididas: miedo a que pudieran hacer algo. Desde la antropolgia, que de nuevo me atrevo a citar, no habría que hablar tanto del "poder del hombre", cuanto del miedo del hombre al posible «poder de la mujer».

De ahí que enseñar a las niñas la obediencia fuera sustancial; no se trataba de evidenciar que la mujer debía obedecer al hombre sino que la obediencia en sí era una virtud. Hay que añadir que en los puntos de las Constituciones que presento todo lo regulado era virtud, algo positivo. $Y$ era virtud no destacar; qué se pretendía con esto. En el punto 43 se decía que las doncellas no trajeran sayas, ni ropas de seda, ni guarniciones costosas, que "no se afeiten ni se enrubien"... "porque así conviene para el servicio de Dios Nuestro Señor y bien suyo".

Me gustaría entrar en la vida cotidiana. Desde las Constituciones o desde los documentos históricos oficiales no se llega a percibir el contenido diario de esta educación. Eso que nos interesa tanto: ei juego de amores y odios, el querer y no querer. Tampoco se llega a los deseos, ese punto tan diluido pero tan sustancial para conocer el mundo vivo, en este caso, del Colegio.

Quisiera que los textos inéditos que presento invitaran, aunque fuera por poco tiempo, a una reflexión. Puede ser que aporten nuevos datos para seguir pensando en el papel de la mujer.

3 Parro, Sixto Ramón, Toledo en la mano. Toledo 1857, t. II, pág. 441. 


\section{REAL CÉDULA DE CONFIRMACIÓN Y AMPLIACIÓN DE LAS CONSTITUCIONES Y NUEVAS ORDENANZAS DEL COLEGIO DE DONCELLAS NOBLES. AÑO 1566}

(Se recogen los puntos dedicados a la atención y educación de las doncellas)

29. Que la Rectora que es o fuere del dicho Colegio coma y cene siempre en el refectorio y duerma en el dormitorio, a donde comieren y durmieren las dichas doncellas. Y si estuviere enferma o impedida legítimamente, que esté y asista en su lugar la provisora o tornera u otra persona que para ello nombrare la dicha Rectora las dichas doncellas y las demás tengan respeto, para que en los dichos lugares se guarde honestidad y recogimiento.

30. Que la dicha Rectora nombre en el dicho Colegio una mujer que sea de mucha confianza y recaudo, para que sea celadora y tenga cargo de tener gran cuenta con las lumbres que se hicieren en el dicho Colegio, y con hacer poner cobro en ellas, y en hacer matar las velas y otras lumbres que hubiere, especialmente de noche, porque a causa de este poco cuidado suelen sobrevenir muy grandes daños y peligros, y es necesario que haya una persona de confianza que tenga cargo de lo sudodicho.

31. Que la dicha Rectora nombre a otra mujer que sea de confianza y de mayor edad que sea escuchadera, para que cuando las doncellas de dicho Colegio, o las demás que dentro estuvieren, hubieren de hablar por las redes del locutorio pueda oir lo que allí hablaren y trataren, y no consienta ni dé lugar a que se hablen ni traten casas deshonestas, ni en perjuicio de las dichas doncellas ni del dicho Colegio; y si se hiciere, que lo reprenda y advierta a la dicha Rectora, para que provea lo que se deba hacer.

32. Que la dicha Rectora no dé licencia a las doncellas para hablar con persona alguna seglar si no fuere con deudos y parientes sin sospecha, y entonces con la dicha escuchadera y por las redes del dicho locutorio, y las menos veces que se pueda; y que no dé lugar ni permita que hablen por la red o ventana que ha de haber en la iglesia del dicho Colegio para recibir el Santísmo Sacramento, ni por los confesores que hubiere para confesar.

37. Que las dichas doncellas se junten todas a hacer labor en una sala del dicho Colegio las horas que hubieren de hacer, la cual sala sea la que en solía ser la Iglesia, porque parece que por ahora es lugar conveniente para ello, y si en tiempo de verano pareciere que conviene bajar a esta sala dormitorio, que al presente está sobre esta misma sala, y mudar el aposento de la labor, que se haga al parecer del Administrador y de la Rectora del Colegio.

38. Que haya maestras en el dicho Colegio para que enseñen a las dichas doncellas a labrar y coser y otras labores que convengan saber, las cuales las puedan corregir y castigar en lo tocante a sus labores y darlas las que hubieren de hacer, y si se excediesen en otra cosa fuera de lo tocante a las dichas labores, el castigo de ello pertenezca a la dicha Rectora; y que también se tenga en cuenta con enseñarlas a leer y escribir, y que la Rectora señale algunas otras doncellas que lo sepan hacer para que ayuden a las nuestras.

39. Que las labores que hicieren las dichas doncellas y lo que ganaren con ellas sea todo para si mismas, porque tengan mayor codicia en aprender y huelguen 
de ocuparse en las dichas labores, con que lo que así ganaren lo haga gastar y emplear la dicha maestra en lo que cada doncella quisiere siendo cosas honestas y convenientes y no lo puedan gastar ni emplear por otra mano, porque se excusen ocasiones de hablar ni tratar con otras personas.

40. $Y$ pues las dichas doncellas han de ser vestidas, alimentadas, enseñadas y dotadas en dicho Colegio, será justo que lo reconozcan, con que cada una de ellas haya de dar y de alguna cosa hecha y labrada de su propia mano para servicio de la iglesia y capilla del dicho colegio, como palias, corporales, paños de manos y otras cosas, conforme a la habilidad y calidad de cada una, y como fuere su voluntad a la cual se deja.

41. Que las doncellas que estén o estuvieren en el Colegio ni pueden recibir ni reciban cartas ni presentes de persona alguna, si no fuere con sabiduría de la Rectora que es o fuere del dicho Colegio, y esto de padre o hermano o de parientes cercanos, y ella no dé lugar a que se reciban de otros.

42. Que las dichas doncellas y Rectora y demás mujeres de clausura del dicho Colegio sean obligadas a confesarse y comulgar las que tuvieren edad para ello y discreción, y las que no tuvieren edad para comulgar han de confesarse los días siguientes: por el día del nombre de Jesús que se celebra en el mes de enero, y la primera semana de Cuaresma, la Pascua de Resurrección y la de Espiritu Santo, el día de la Visitación de Nuestra Señora, el día de la Natividad de Nuestra Señora, la primera de Adviento y la Pascua de Navidad de Nuestro Señor.

43. Que las doncellas que estuvieren en el dicho Colegio, no puedan traer ni traigan sayas, ni ropas de seda, ni guarniciones costosas, ni se afeiten ni enrubien, porque así conviene para el servicio de Dios Nuestro Señor y bien suyo; y por esto no se quita, antes se encarga, que se tenga en cuenta con hacerlas andar bien aseadas, ataviadas y limpias, y que las hagan lavar las cabezas cuando to hubieren menester; y por evitar entre las doncellas bandos y parcialidades sobre presumir cada una ser mejor que las otras, mandamos que ninguna de ellas se ponga DON durante el tiempo que estuvieren en dicho Colegio, pues ninguna de las parientes del Cardenal se lo ha puesto.

44. Y cuanto a los alimentos que de ordinario se han de dar a las dichas doncellas y las demás, mandamos que a cada una de las que estuvieren dentro de la clausura, se les dé una libra de carnero cada día para comer y cenar, y entre doce doncellas dos reales para ante y pos, y que se tenga en cuenta con dar alguna cosa que almuercen y merienden las niñas que fueren de tan poca edad que tengan de ello necesidad a disposición de la Rectora del dicho Colegio; y que los días de Pascua o fiestas señaladas se les dé algún extraordinario, al parecer y disposición del Administrador y Rectora, a los cuales se encarga que en esto tengan moderación, de manera que no se haga gasto demasiado, y que los días que no fueren de carne se den las comidas y raciones conforme al gasto que con cada una se hace los días de carne, y entiéndase que todo se ha de guisar y aderezar a costa de dicho Colegio al parecer y disposición de la dicha Rectora, y que se les ha de dar el pan que hubieren menester como ahora se hace; y que se compre el tocino que fuere necesario para la provisión como parece que hasta aquí se ha hecho.

45. Que a las doncellas que son y fueren del dicho Colegio, no se les dé vino alguno ni consientan que lo beban, sino fuere con necesidad y por mandato del médico de la dicha casa y durante el tiempo que durare la dicha necesidad y no más; y en lo que toca a la Rectora y a las demás mujeres ancianas que hubiere 
para el servicio del dicho Colegio se les dé el vino que hubiere menester para las dichas comidas al parecer del Administrador y Rectora.

46. Que en lo que toca a las que estuvieren enfermas dentro del dicho Colegio que se les dé cumplidamente lo que hubieren menester, según se ordenare por el médico del dicho Colegio que las curare y visitare.

47. Que a ninguna doncella ni a otra alguna de las que estuvieren dentro de dicha clausura se les pueda dar ni dé ración en dinero ni se les consienta vender pan ni vino ni otro mantenimiento de los que metieren en el dicho Colegio para su provisión.

48. Para que la Rectora y doncellas que están y estuvieren en el dicho Colegio sepan y entiendan como se han de repartir ell tiempo y en lo que se han de ocupar, mandamos se guarde el orden siguiente:

49. Primeramente: que desde el día de Pascua de Resurrección hasta el fin de mes de septiembre, se levanten entre las cinco y seis horas de la mañana, y desde el primer día del mes de octubre hasta la Pascua de Resurrección de seis a siete, y estando vestidas y aderezadas, luego todas juntas dirán las Horas de Nuestra Señora, en tono bajo hasta Nona, y acabadas de decir estas Horas, estudiarán la doctrina cristiana y luego irán a oir Misa Mayor; y porque habrá mujeres al servicio y otras que tienen otros oficios en el Colegio que no podrán asistir a la Misa Mayor, se dirá una Misa rezada antes de la Mayor, para que la puedan oir y oigan estas mujeres que tuvieren los tales oficios y hubieren de servir la casa.

51. Que desde el día de Pascua de Resurección hasta el último de septiembre comerán a las diez horas, todas juntas en su refectorio, y desde el primer día del mes de octubre hasta Pascua de Resurreción a las once, y en habiendo comido darán gracias y dirán las oraciones siguientes en tono bajo: «El Ave Maris Stella y O gloriossa dominam, y al cabo dirá la Rectora o la que estuviere en su lugar: "Ora pro nobis sancta Dei genitrix etc: Domine, exaudi orationem meam: concédenos famulos tuos" y una oración por el ánima del Cardenal fundador y otra "Fidelium Deus", por todos los difuntos y bienhechores del dicho Colegio, y acabar con: «Fidelium animae per misericordiam Dei requiscant in pace» y responderán "Amén", y se hincarán de rodillas a rezar un Pater Noster y una Ave María hasta que la Rectora o la que en su lugar presidiere les haga la señal para que se puedan ir.

52. Que en el verano podrán dormir siesta de doce a una, y de la una hasta las cuatro, en verano y en invierno, harán y aprenderán labor y a leer y escribir.

53. Que desde las cuatro a las cinco podrán holgar y descansar, y a las seis horas todas juntas dirán en tono bajo Vísperas, Completas y Maitines de Nuestra Señora.

54. Hecho lo susodicho podrán cenar a las siete en verano y en invierno, y al tiempo de comer y cenar leerán libros de santas doctrinas.

55. Después de haber cenado, como dicho es, desde las ocho hasta las diez, velarán en sus labores y en leer y escribir, a las diez se podrán acostar, y al tiempo de acostar todas juntas en su dormitorio, cada una de ellas hincada de rodillas delante de su cama, el rostro vuelto a una imagen de Nuestra Señora que tendrá a su Hijo precioso en los brazos, puestas las manos comenzará la Rectora, o la que estuviere en su lugar, y todas la ayudarán y dirán las oraciones siguientes: "Sálvanos Domine vigilantes etc." y otras oraciones, las que a la Rectora pareciere, y dichas se acostarán. 
56. Que en dicho Colegio haya una enfermeria, la cual parece que estará bien en el cuarto del Mediodía, y en la sala pueden estar las enfermas y en la cámara las convalecientes.

57. Que se reciban dos mujeres para el servicio del dicho Colegio que sirvan dentro de la clausura de él para barrer, fregar y sacar agua, y para amasar y cocer las cuales sean de fuera de la ciudad de Toledo, si pareciere al Administrador y Rectora que son necesarias más sirvientas, las pueden recibir con salario conveniente, según que con ellas se concertare; y encargamos a la Rectora que es o fuere del dicho Colegio que mande a las doncellas que en él hubiere y tuvieren edad para ello que ayuden al amasar y cocer el pan, y a otras cosas que tendrán necesidad de saber, para que lo aprendan y sepan, y lo que sepan mandar y hacer si fuere necesario en sus casas cuando salgan del dicho Colegio.

58. Que en el abrir de la puerta de clausura del dicho Colegio se tenga mucho cuidado y recato para que se abra las menos veces que se pueda, y que las mujeres que dentro entraren sean madres o parientas muy cercanas de las doncellas que dentro estuvieren, y que entonces entren con licencia del Administrador y Rectora y sus rostros descubiertos sin arrebozo ni encubierta.

59. Que las doncellas que fueran niñas menores de doce años coman juntas en el refectorio a una parte de él, y que se siente con ellas una mujer de recaudo que tenga cuidado de hacerlas comer con las otras doncellas menores, y se sientan conforme a la antigüedad de la entrada que cada una tuviere; por manera que aunque después de la que así hubiere comido en la mesa de las niñas hayan entrado otras mayores, no se les pueda preferir por haber estado y comido en la mesa de las niñas; y que en el refectorio se sirva a las dichas doncellas por su antigüedad.

60. Que se reciba en la Clausura del dicho Colegio una mujer de recaudo que solamente tenga cuenta y cargo de lavar y tocar y limpiar y coser a las niñas que estuvieren en el dicho Colegio y no tuvieran discrección ni edad para saberlo hacer, y si las sobrase tiempo haga lo que la mandare la Rectora, la cual dicha mujer parece que podrá servir de celadora de las lumbres de día y de noche, conforme al capítulo que sobre ello dispone.

61. Que por cuanto no hay cosa que en las casas de comunidad más daño haga que la inobediencia, y más perturbe la disciplina religiosa y cristiana, se manda: que así la provisora y doncellas como las demás mujeres que al presente están y de aquí adelante estuvieren en la clausura del dicho Colegio, sean obedientes a la Rectora y a lo que les mandare o quien sus veces tuviere, y no haciéndolo las castigue con rigor conforme a la calidad del exceso o delito que hicieren, y que estas penas ejecuten el Administrador y la Rectora.

62. Que las Constituciones del dicho Colegio y esta misma Cédula estén escritas en una tabla de la clausura en la sala de la labor y también en el refectorio y dormitorio, para que así la Rectora como todas las doncellas y las demás mujeres de la clausura del dicho Colegio sepan y entiendan lo que son obligadas a hacer cumplir en casa uno de los lugares susodichos.

63. Que todas las informaciones que de aquí en adelante se hicieran de las doncellas que en el dicho Colegio hubieren de ser recibidas se hagan en sus naturalezas, como mandan las Constituciones; so pena que el Administrador que lo contrario hiciere sea privado de su oficio y en la misma pena incurra la Rectora que contra la forma susodicha las recibiere en la Clausura del dicho Colegio; y que la doncella que de otra manera fuere recibida sea expelida del Colegio hasta 
que haga dicha información en su naturaleza como dicho es; porque de otra manera no puede constar bien de la limpieza de ellas; y después de traídas las dichas informaciones las lea el Escribano del dicho Colegio, que ha de sei cristiano viejo como los demás oficiales, delante del Administrador y Rectora y de los letrados del dicho Colegio o de alguno de ellos, que también han de ser de las calidades del Administrador y Rectora; para lo cual se junten todos en el recibimiento del dicho Colegio para leerlas, para que a todos conste de la limpieza de las que se reciben, $y$ no pueda haber engaño en esto; $y$ entre tanto que hay Archivo donde se han de poner las dichas informaciones, haya un arca con tres llaves que se pongan; y que no se pueda recibir ninguna doncella por otras informaciones hechas por otras personas, sino por las informaciones que se hicieren por parte del Colegio.

79. Que los Capellanes que hubieren de ser nombrados por confesores de las doncellas sean doctos para el dicho efecto, honestos y de buena vida para que las sepan excitar a la virtud, honestidad y obediencia.

81. Que en cada año para siempre jamás se hagan en el dicho Colegio dos fiestas señaladas con sus Vísperas en memoria por el ánima del Cardenal, la una del nombre de Jesús, de quien el dicho Cardenal fue muy devoto, y la otra de Nuestra Señora, con quien tuvo también muy grande devoción, y será de la Visitación de Nuestra Señora, en las cuales haya sermón y toda solemnidad y procesión dentro del claustro del Colegio, en la cual vayan la Rectora y provisora y doncellas y maestras que hubiere en dicho Colegio con sus vestiduras de colegialas y velas en las manos; y porque fue la voluntad de dicho Cardenal a que fuesen vistas las dichas doncellas, por lo que toca a sus casamientos, parece ser cosa necesaria y asi mandamos que se haga una ventana que salga de la Iglesia al dicho claustro con sus rejas y buenas cerraduras, para que por ella puedan ser vistas con toda honestidad y decencia, las cuales no se puedan abrir ni se abran sino durante el tiempo que se hicieren dichas procesiones. 